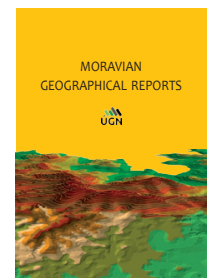

\title{
The diffusion and development of time-geography in East Asia: The academic life paths of two key scholars
}

\author{
Chunjiang LI ${ }^{\text {a }}$, Yanwei CHAI ${ }^{\text {* }}$, Yoshio ARAI ${ }^{\mathrm{b}}$
}

\begin{abstract}
A summary of the diffusion and development of time-geography in East Asia, specifically in Japan and China, is presented in this article. Previous studies have provided reviews of time-geographic research and spacetime behaviour research in both countries. Few studies, however, have told the story about how and why timegeography diffused into East Asia. By showing and analysing the academic life paths of Yoshio Arai and Yanwei Chai, we conclude that the development of time-geography in Japan and China goes hand in hand with their academic progress. Moreover, the interactions within their academic life paths mark some key events that promoted time-geography significantly. The similarities and differences between their academic life paths are also analysed in this article. Both scholars shared some common research topics, such as childcare problems, urban spatial structures and socioeconomic transformations, which were also the most prominent characteristics of time-geography in East Asia. In addition, the socioeconomic backgrounds of their academic life paths are also quite similar, which reflects the close relationship between time-geography and societal needs. Finally, this article discusses the effectiveness and disadvantages of the academic life path method, as the method has proven to be an important tool in analysing the role that key scholars play in promoting a certain discipline. In conclusion, the diffusion and development of time-geography in East Asia can hardly have happened without both individual scholars' hard work and the exchange and cooperation activities between scholars.
\end{abstract}

Key words: time-geography, life path, academic history, Chinese geography, Japanese geography

Article history: Received 1 March 2020, Accepted 25 September 2020, Published 31 December 2020

\section{Introduction}

Time-geography was established by Hägerstrand (1970, 1982) and his colleagues in Sweden. It emphasises the physical existence and indivisibility of human beings and analyses the "choreography" of individual existence within space and time (Pred, 1977; Hägerstrand, 1975). The daily activity sequence is depicted as a path through space-time, and three major constraints, namely, capability constraints, coupling constraints and authority constraints, are analysed to understand the interactions between individual humans and society (Pred, 1973; Hägerstrand, 1970, 1982). Over the past 40 years, timegeography has been developed and applied in a variety of aspects, including urban planning, the evolution of regions and landscape, the diffusion of innovation, migration and urban growth, individual everyday life, travel behaviour and accessibility (Pred, 1977; Ellegård, 1999; Ellegård and Svedin, 2012; Kwan and Weber, 2003). Recently, timegeographers have paid attention to some lesser-known concepts such as 'project' and 'pocket' of local order (Ellegård and Vilhelmson, 2004; Lenntorp, 2004). Some new research directions have been suggested, including domestic activity and energy consumption, information and communications technologies (ICTs) and their effects on everyday life, as well as segregation and health research from the perspective of individual activity (Elleglrd and Palm, 2015; Thulin and Vilhelmson, 2012; Shaw and Yu, 2009; Kwan, 2013).

After its establishment in Sweden, time-geography has diffused throughout the world, including the United Kingdom, the United States, the Netherlands, Japan and China, and associated with local contexts and societies (Ellegård, 2018a). The development of time-geography in East Asia, especially in Japan and China, emphasised the application of a timegeographic approach to social issues, as well as urban planning. At the same time, the applications contributed to the innovation and extension of time-geography.

Several studies have reviewed processes of the introduction and diffusion of time-geography and the vast amount of timegeographic research in East Asia. For example, Okamoto and

\footnotetext{
${ }^{a}$ College of Urban and Environmental Sciences, Peking University, Beijing, China (*corresponding author: Y. Chai, e-mail: chyw@pku.edu.cn)

${ }^{\mathrm{b}}$ Department of Regional System Sciences, Graduate School of Arts and Sciences, The University of Tokyo, Tokyo, Japan
} 
Arai (2018) give a detailed overview of how time-geography was introduced into Japan, adopted by geographers and used in urban life and societal problems. One of the most important works is an anthology containing several translated timegeographic classical articles, by Arai and other members in the Time-Geography Study Group (Arai et al., 1989). Moreover, several empirical studies about childcare problems from a time-geographic perspective have also helped to understand the burdens mothers with children face in urban life.

Chai (2013) first provided a review of space-time behaviour research in China, which is largely built on the theoretical framework of time-geography. Analytical methods and data collection techniques are the two main foci, and he pointed out three main research themes: understanding urban spatial structures from an individual activity perspective; understanding space-time behaviour in the transitional context; and implementing the space-time approach in transportation and planning practice. Some detailed information and other research topics regarding social equity and environmental sustainability were added in Chai et al. (2015). Lately, Chai et al. (2016) has provided an overview of behavioural geography research in China, including theoretical, empirical and applied research in behavioural analysis. Empirical research topics covered some continuing key themes, including socio-spatial reconstruction, relationships between urban forms and individual behaviours and spatial cognition. Some recent trends were also mentioned, including social equity, segregation, social change, social networks, activity-travel patterns, environmental pollution and health geography. In summary, time-geography and its related spacetime behavioural approach in China are accepted and widely used by urban geographers, transportation researchers and urban planners to understand the interaction between urban space and individual activities.

We could conclude from the above review papers that Professor Yoshio Arai from the University of Tokyo and Professor Yanwei Chai from Peking University are the two key scholars, who have played an important role in introducing and developing time-geography in Japan and China, respectively. Arai formed a time-geography study group in 1987. The group members selected and translated influential studies made by renowned Swedish and American time geographers, including Torsen Hägerstrand, Allen Pred, Solveig Mårtensson, Bo Lenntorp and Kajsa Ellegård (Arai et al., 1989). They also conducted three activity diary surveys in Shimosuwa, Kawagoe and Nisshin, and published several empirical research papers about the daily activity of urban residents (Okamoto and Arai, 2018). Some of the group members continued to conduct time-geographic research after the group was cancelled (e.g. Arai, 2003; Okamoto, 2003). Chai, on the other hand, brought timegeography into China. Several introductory papers were published by him and by his research team (Chai and Wang, 1997; Chai et al., 2000; Chai, 1998; Liu and Chai, 2001). Several activity diary surveys were conducted in Dalian, Tianjin, Shenzhen, Beijing and Xining, and much space-time behaviour research was published by them. Chai also trained several leading urban geographers who dedicated themselves to time-geographic and related space-time behavioural research. Moreover, interactions and cooperation between these two scholars also helped to promote understanding daily activities in their own countries.

Only a few studies, however, have considered reviewing the contribution of these two scholars from the perspective of their academic experiences and interactions. The developmental trajectory of time-geography in East Asia is also unclear. Pred (1977) pointed out that time-geography could also be applied to the intellectual history of a discipline or an academic school of thought by depicting and analysing the convergence and divergence of the life paths of key individuals, except for urban planning and some research themes in human geography. Similar to the daily path, the life path is a continuous line starting from the point of birth and ending at the point of death, depicting individual activities in time- and space-coordinates (Pred, 1973). On the other hand, unlike the daily path, the time scale of the life path is the whole life, and stations in the life path are usually the cities the individual has encountered. In this paper, we focus on academic activities. We use the concept of the academic life path to describe and analyse where, when and what academic activities scholars did from the time they entered college until now. Interactions between scholars were also analysed using bundles. The information on academic activities and interactions were mainly gathered by interviews with the scholars and their published articles. By summarising the diffusion and development of timegeography in East Asia from the perspective of the academic life paths of two key scholars, namely, Yoshio Arai and Yanwei Chai, this article aims to:

1. Demonstrate the effectiveness of the life path method in the study of academic history. Compared with other methods, the life path method can provide a clearer developmental trajectory of a certain discipline and highlight the importance of interactions between key individuals;

2. Provide a scheme for studying the diffusion and developmental history of a discipline. Many modern disciplines originated from Europe and diffused first into other Western countries, such as the United States, and second, into East Asia. Time-geography is one of these disciplines. In addition, the developmental process of time-geography is relatively easy to capture. Therefore, studying time-geography can provide a good example for other disciplines; and

3. Figure out how exactly time-geography diffused into East Asia, specifically Japan and China, and why timegeography developed differently in these two countries.

In the following section, we first provide an overview of the acceptance and evolution of time-geography in Japan from the perspective of the academic life path of Yoshio Arai. Next, a summary of the diffusion and development of time-geography in China is presented based on the academic life path of Yanwei Chai. We then focus on the interaction between these two scholars and highlight the important events that had a great influence on the development of timegeography in East Asia. Similarities and differences between their academic life paths are analysed in the next section. Meanwhile, it is also important to analyse the influence of social and economic contexts on academic life paths. Finally, we discuss and conclude the findings of this article with the strengths of the life path method.

\section{Academic life path of Yoshio Arai and the acceptance and evolution of time-geography in Japan}

Arai first formed a study group to systematically learn and introduce time-geography against a background of social-oriented transformation in Japan. He then conducted several activity diary surveys and some time-geography 
research. After that, his cooperation with Chai diffused timegeography into China, as well as benefitted the development of time-geography in Japan. Finally, Arai switched his research interest into ICTs and daily life. The academic life path of Yoshio Arai is shown in Figure 1.

\subsection{Time-geography's beginnings in Japan}

Time-geographic studies began in Japan before anywhere else in East Asia, which was probably the earliest start after Europe and the United States. Japanese geographers were first informed about time-geographic studies in the mid 1970s, shortly after their birth in Sweden. A representative geographer who introduced quantitative geography to Japan, Professor Teruo Ishimizu at Nagoya University, had visited Lund University. His book, "An Outline of Quantitative Geography", was published in 1976 and it was the first Japanese textbook on quantitative geography (Ishimizu, 1976). His book included an explanation of the modelling of migration and Hägerstrand's theory of spatial diffusion. He concluded with a discussion of time-geography as the latest research trend. In his book, he used the English name, i.e. "time-geography", since the Japanese translation "Jikan Chirigaku" had not yet been coined.

"Jikan Chirigaku" may have been used for the first time in a 1985 paper written by Keiji Kushiya, which was published in the Geographical Review of Japan (Kushiya, 1985a). Kushiya's paper, which was titled "Time-geographic interpretation of fisherman's daily activity on Tokyo Bay, Japan", is the earliest empirical study to focus on people's daily activities from a time-geographic perspective. Kushiya's work was not popular among Japanese geographers, however, because it explored a ontypical case, i.e. the daily activities of fishermen.

\subsection{Japanese retail industries: Business trends and their interest in "time"}

Yoshio Arai first heard about time-geography around the time Kushiya's paper was published. At that time, he was teaching business administration and studying retail geography. Therefore, he was interested in new forms of retailing in Japan.

At that time, convenience stores were attracting much attention. Time is a decisive factor for convenience stores, in that the store should be open from the early morning to late at night. For example, 7-Eleven is a convenience store chain that originated in the United States and is the largest convenience chain both in Japan and in the world. Its name means "service from 7 o'clock to 11 o'clock", which suggests that time had become recognised as a principal issue in this retail industry.

The critical issue behind Japanese retailers' attention to time was their interest in the so-called "time-shift business." Time-shift business refers to a business model with operating times that are extended beyond traditional times. Convenience stores and midnight restaurants are typical examples of time-shift businesses. In addition to these new forms of retail and restaurants, businesses appealing to time factors, such as "overnight delivery services" or "same-day delivery services", became popular. New flexible working styles were also proposed, such as the Flextime system. Thus, the interest in time increased in every industrial sector during this period.

The Japanese government paid attention to this increased interest in "time". A report edited by the Economic Planning Agency titled 'Time and Consumption' observed the growing importance of time-consuming consumption and timecreating consumption (Economic Planning Agency, 1987). The reports listed several examples of businesses corresponding to these new types of consumption, such as urban amusement parks, gourmet lifestyles, vacation homes, food delivery services and home shopping. By the mid-1980s, Japan was in an "era of time".

Given these trends, Arai considered convenience stores as an additional target for his research studies in the field of retail studies. He attempted to apply the concepts of timegeography as a theoretical framework to the study of timeshift businesses.

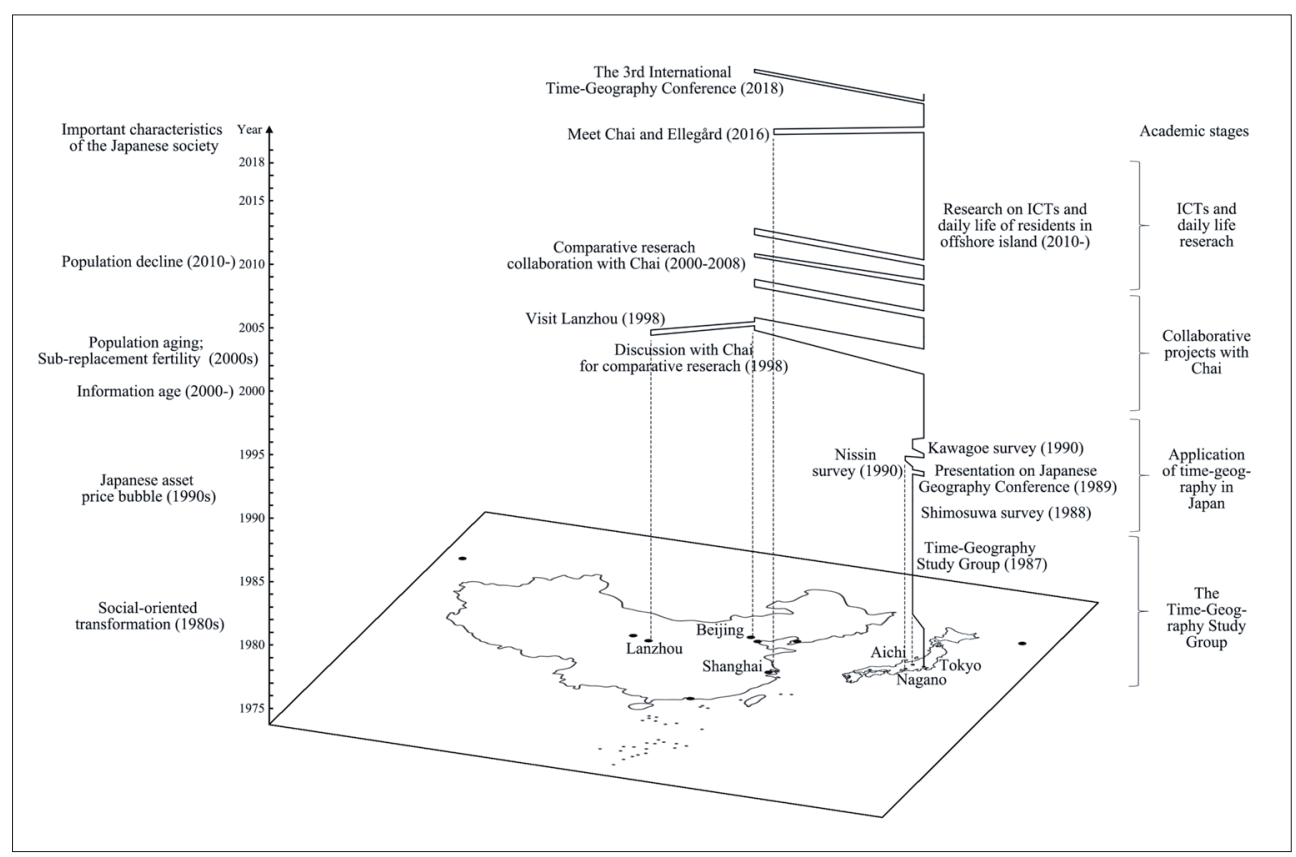

Fig. 1: Important characteristics of the Japanese society, the individual life path showing the locations and years of Arai's geographical movements and main academic activities, and the academic stages of Arai Source: authors' elaboration 


\subsection{Establishing the Time-Geography Study Group}

To his credit, however, Arai realised that he could not fully grasp the time-geographic perspective because he was unable to obtain the materials introducing the research methods and study cases in this research field. Therefore, he attempted to gather as many articles as possible, read them and sort them out. He also tried to encourage other people to collect time-geographic literature. Several graduate students from the University of Tokyo and Nagoya University responded to his private call for collaboration. In February 1987, they held their first meeting, and the "Time-Geography Study Group" was formed. The initial members of this group were Taro Kawaguchi and Satoru Hiromatsu from the University of Tokyo, and Kohei Okamoto and Hiroo Kamiya from Nagoya University.

The Time-Geography Study Group met approximately 20 times over about two years, and they discussed many domestic and foreign articles. Thus, the entire field of timegeography could be captured through their work. In the discussions during the meetings, they shared an intention to publish the outcome of their group work and make timegeography widely known not only to geographers, but also to stakeholders concerned with the social issues of urban society. Representative articles were selected from the time-geography field and translated into Japanese in order to publish an anthology. Eight articles in total were finally selected, and the anthology, "Space of Life Time in the City", was published in the spring of 1989 (Arai et al., 1989).

\subsection{Empirical study of the daily activities of urban residents}

After publishing the anthology, Arai and the other group members thought that the next step would be empirical studies in Japanese cities; however, they were not sure about what method to use in this study.

The first challenge was the acquisition of daily activity data, which would provide the necessary materials for the empirical study. They considered using existing official statistics, such as person-trip surveys. But there was no alternative but to conduct original surveys because of the limitations of the sampling methods and data items in the existing statistics.

Fortunately, the group had the opportunity to conduct a survey to collect basic data materials to establish a promotion policy for local retail businesses. This survey was conducted in Shimosuwa Town, Nagano Prefecture, which was close to Arai's university at that time. As mentioned earlier, the possibility for time-shift businesses was a 'hot' topic in Japanese business society. This survey targetted the daily life of residents from a "space and time" perspective. The framework of the survey was a good fit for time-geography.

The next challenge was to design the questionnaire. They took note of the "Activity Approach", which was developed in transportation planning. In particular, a 1983 report, Understanding Travel Behaviour, by the Transport Studies Unit (TSU) at Oxford University, drew their attention; it proposed using an "activity diary" to collect the details about people's daily activities (Jones et al., 1987). Thus, the activity diary concept was applied in the design of the survey questionnaire. The final version of the questionnaire was consistent with an activity diary, as it recorded the activities successively on the investigation day, and a trip record, as it collected the details of trips made on the same day (Fig. 2). The respondents were requested to complete both forms.

Through the Shimosuwa study, the framework of timegeographic research was established. They then planned daily activity surveys in large metropolitan areas as the next step. It took nearly two years to obtain a research grant and conduct the surveys. Two daily activity surveys were conducted: one at Nisshin Town in the suburbs of Nagoya early in the summer of 1990, and the other at Kawagoe City in the suburbs of Tokyo in the fall of 1990.

The data collected from these three surveys were analysed from various perspectives, and the results were published as "Space and Time in the City" (Arai et al., 1996).

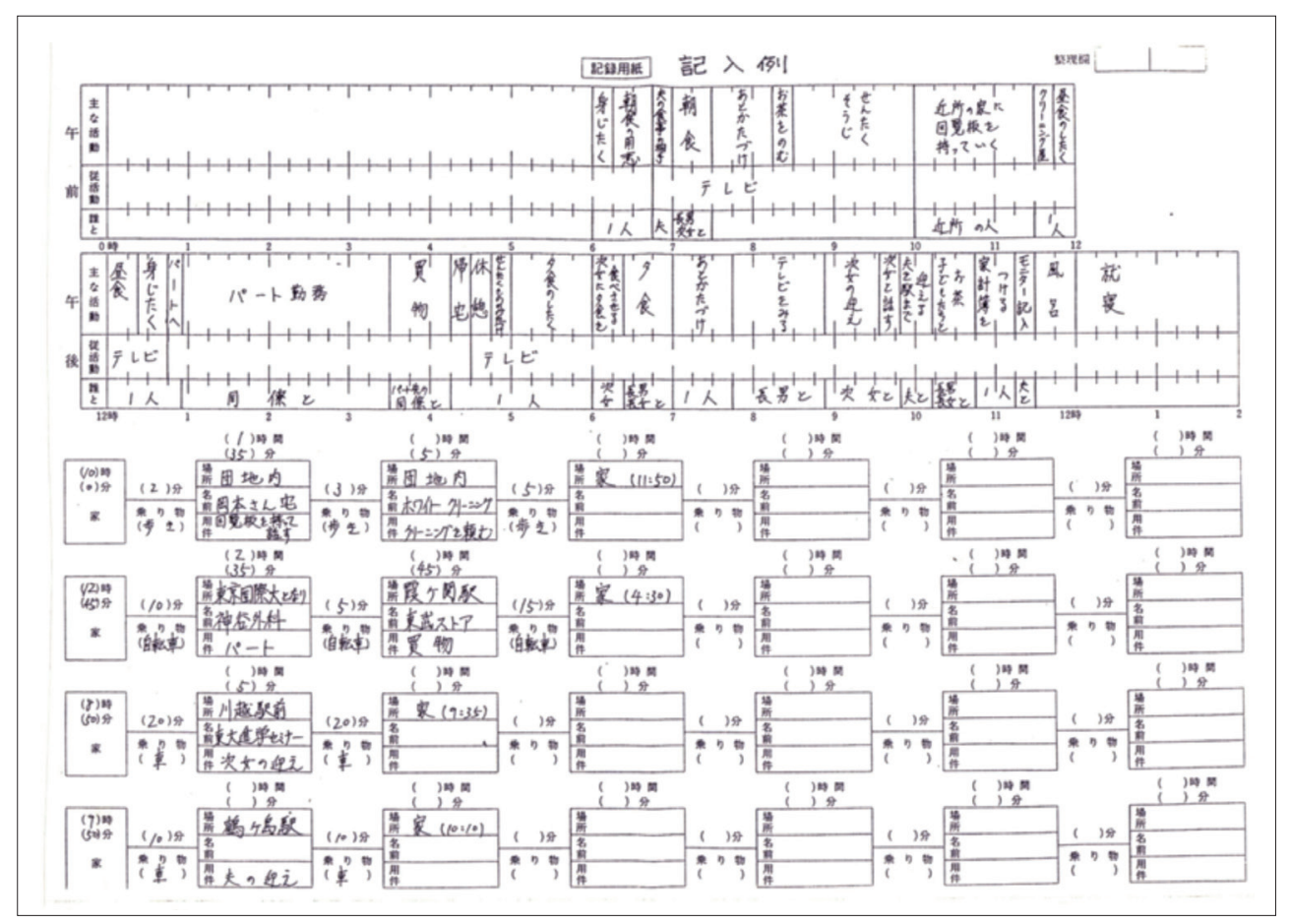

Fig. 2: Final version of the questionnaire used in Shimosuwa survey

Source: authors' elaboration 


\subsection{Characteristics of Japanese city life revealed by the daily activity surveys}

Some basic characteristics of Japanese city life were revealed in the data collected from the daily activity surveys conducted in the three Japanese cities. Arai and his colleagues were impressed by the fact that gender was the most fundamental feature of daily activities in Japanese cities. Although these three cities were different in location and size, the temporal patterns of going out were quite similar in the three cities. Obvious differences could be seen in the patterns of male and female activities. Almost all husbands left their homes at approximately 8:00 am and returned at approximately 6:00 pm on weekdays. Most wives, however, went out between 10:00 am and 4:00 pm, with no more than $70 \%$ of wives leaving their homes daily (see Fig. 3).

A close examination of the activity patterns shows some characteristics of the work conditions for married women in the cities. The proportion of women who were not working was quite high for mothers with infants. Although the number of working mothers gradually increased after their children reached school age, they only went out for short periods because most of them worked part-time.

When he saw these results, Arai intuitively knew that Japanese time-geographic studies could contribute most effectively to the issue of "quality of life" for mothers with small children. Thereafter, heand his research team continued to analyse the influence of child rearing on mothers' quality of life. These analyses showed that Japanese childcare systems and day care facilities could not sufficiently meet the recent actual conditions and needs of Japanese society. Consequently, Japanese mothers must endure all the stress from this mismatching of facilities and needs.

Today, the Japanese government has proposed to "build a society where women can succeed." On the other hand, they have been aware of this issue for 30 years!

\subsection{Penetration of the interest in quality of life and the "geography of daily life"}

Since the publication of "Space and Time in the City", Japanese geographers have become aware that the "quality of life" can be a matter of geographical study, which is also related to the background of population aging, subreplacement fertility and population decline, faced by Japanese society in the 2000s and 2010s.

For instance, one of Arai's former students, Mikoto Kukimoto, pursued her studies of child rearing and mothers' quality of life and completed her doctoral thesis. Her thesis is probably the first geographical thesis to consider the issue of child rearing. In 2016, her thesis, including later study results, was published as "Geography of Childcare and Parenting Support” (Kukimoko, 2016).

Hitoshi Miyazawa and his colleagues at Tokyo Metropolitan University proposed analysing local welfare conditions using the new mapping and GIS techniques in their 2005 book, "Applied Cartography and GIS for Welfare and Well-being" (Miyazawa, 2005). They employed activity dairies similar to Arai's survey to deal with the issues of gender and women's social participation. In addition, they applied simulation techniques based on Lenntorp's method (Lenntorp, 1976).

Thus, the interest in the various challenges experienced by women and the elderly during their daily lives has increased since the end of the 1990s. A new study field was established, namely, the "Geography of Daily Life." Representative publications are "Urban Spaces of Working Women" by Yoshimichi Yui and colleagues; "Women's Employment and Life Space", edited by Yoshimichi Yui; and "Geographical Analysis of Social Services for the Elderly in Japan” by Shinichiro Sugiura (Sugiura, 2005; Yui et al., 2004; Yui, 2012).

The daily life and welfare of suburbanised residents and factory workers also received attention from one of the TimeGeographical Study Group members, Kohei Okamoto, and his student, Yuichiro Nishimura. Okamoto (1997) investigated the daily lives of suburban people and their relationship to the suburbanization of Tokyo. Nishimura and Okamoto (2001) examined the daily lives of workers undertaking two shifts, day and night, in Toyota automobile factories.

Meanwhile, the issue of the consistency of women's work and child rearing lives is one of the main study objects in the geography of daily life. These studies are strongly influenced by previous time-geographic studies. It is sure that Arai's work exposed the problem from a time-geographic perspective and made some significant contributions to the development of this new study field.

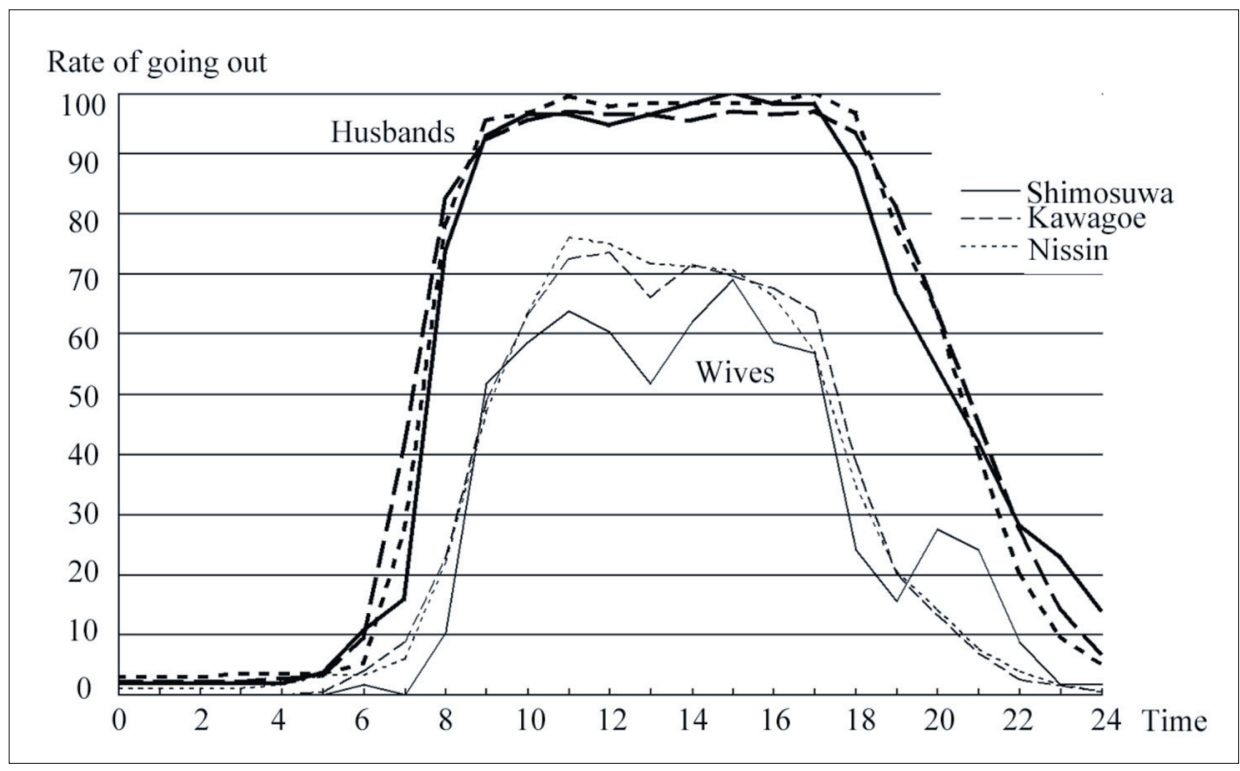

Fig. 3: Temporal patterns of going out in Japanese cities. Source: Arai et al., 2008 


\subsection{Diffusion of time-geography into East Asia}

The focus on empirical studies on quality of life has been a feature of Japanese time-geographic studies. This feature appears to have diffused to neighbouring countries. For example, Arai and Chai conducted a joint comparative study, which helped gain an understanding of urban life in both countries from a time-geographic perspective.

In this study, Arai took charge of the comparative analysis of the general characteristics of daily activities between Japanese and Chinese cities. The results were striking. In contrast to the Japanese cases, the difference by cities was clear, but fewer gender differences were found in the Chinese data (see Fig. 4)

From the beginning, childcare facilities and services in Chinese cities were established to enable both parents to work full-time. For a long time, however, many Japanese have been conscious that it is difficult for both parents to combine careers and child rearing. Nevertheless, the Chinese experience shows that this attitude might be misguided.

Since this comparative study, the condition of childcare services in Japanese cities has largely improved. The standards of services in Japanese cities, however, have not yet matched those in Chinese cities. The issue of children on waiting lists has drawn wide social interest in recent years. Despite a slogan by the Japanese government, "Success of Women in the Workplace", many challenges remain.

\subsection{ICTs and daily life research}

Arai changed his research interest to ICTs and the daily life of residents on offshore islands after the joint comparative study with Chai in 2008. Several articles were published, including those on government policy, Internet access, and the daily activity of residents in low-density areas, such as the offshore islands (Arai et al., 2012; Stake and Arai, 2013, 2017).

Although there has been no remarkable progress in timegeography since the mid-2000s in Japan, probably due to strict concerns about privacy derived from individual data from GPS and mobile phones, Arai's research was still influenced by time-geography and behavioural perspectives.

\section{Academic life path of Yanwei Chai and the diffusion and development of time- geography in China}

Chai first learned time-geography when he was studying in Japan. Two activity diary surveys were conducted in Hiroshima and Lanzhou with the help of Arai. After he returned to China, Chai continued his time-geography research and cooperated with Arai for the joint comparative study. Since 2010, Chai has contributed to innovations in time-geography methodology and urban planning studies. He has also communicated with international

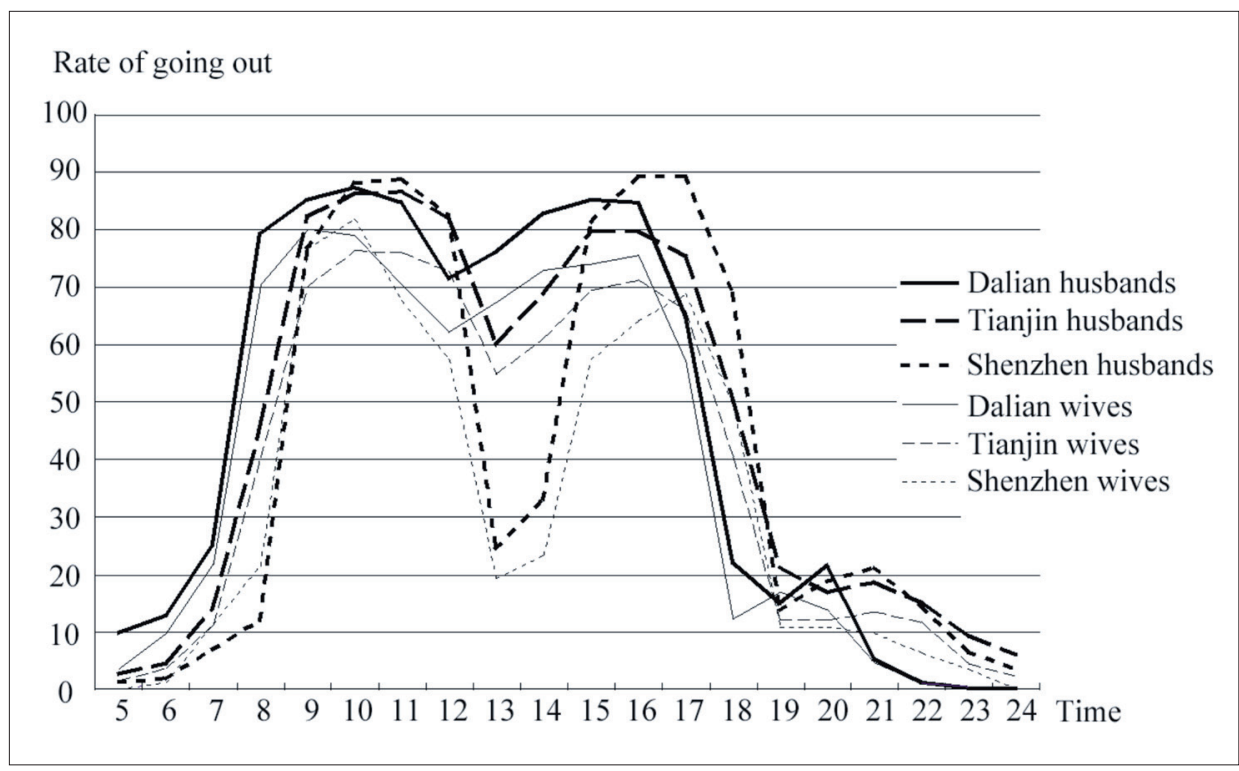

Fig. 4: Temporal patterns of going out in Chinese cities. Source: Arai et al., 2008

time-geographers extensively, which considerably helped his research. Chai's academic life path was tightly related to the development of Chinese cities. The academic life path of Yanwei Chai is shown in Figure 5. The two main backgrounds that significantly influence Chai's academic life are the rapid urbanisation and suburbanisation experienced by Chinese cities, especially after the reform of the housing system in 1998, and the "New Urbanisation" policy, which accelerated social-oriented transformation in Chinese society.

\subsection{Before exposure to time-geography}

Chai was studying geography in Northwest Normal University in Lanzhou for his bachelor degree. At that time, influenced by the Soviet Union, the distribution of industry was the focus of economic geography. The main method of research was regional description, and quantitative analysis was seldom performed. Even during his master's study, Chai had never had an opportunity to read an English article or book on geography and had never heard about urban geography, behavioural geography and time-geography, because of a lack of resources and rigid thinking. Regardless, Chai was active in promoting a revolution in Chinese geography. He held and participated in several workshops and forums for young geographers and learned about the quantitative revolution for the first time in 1985.

\subsection{Initial learning about time-geography}

In 1988, Chai was chosen as an exchange student to Hiroshima University in Japan, sponsored by a Japanese Government Scholarship. The exchange program changed his academic life substantially. 


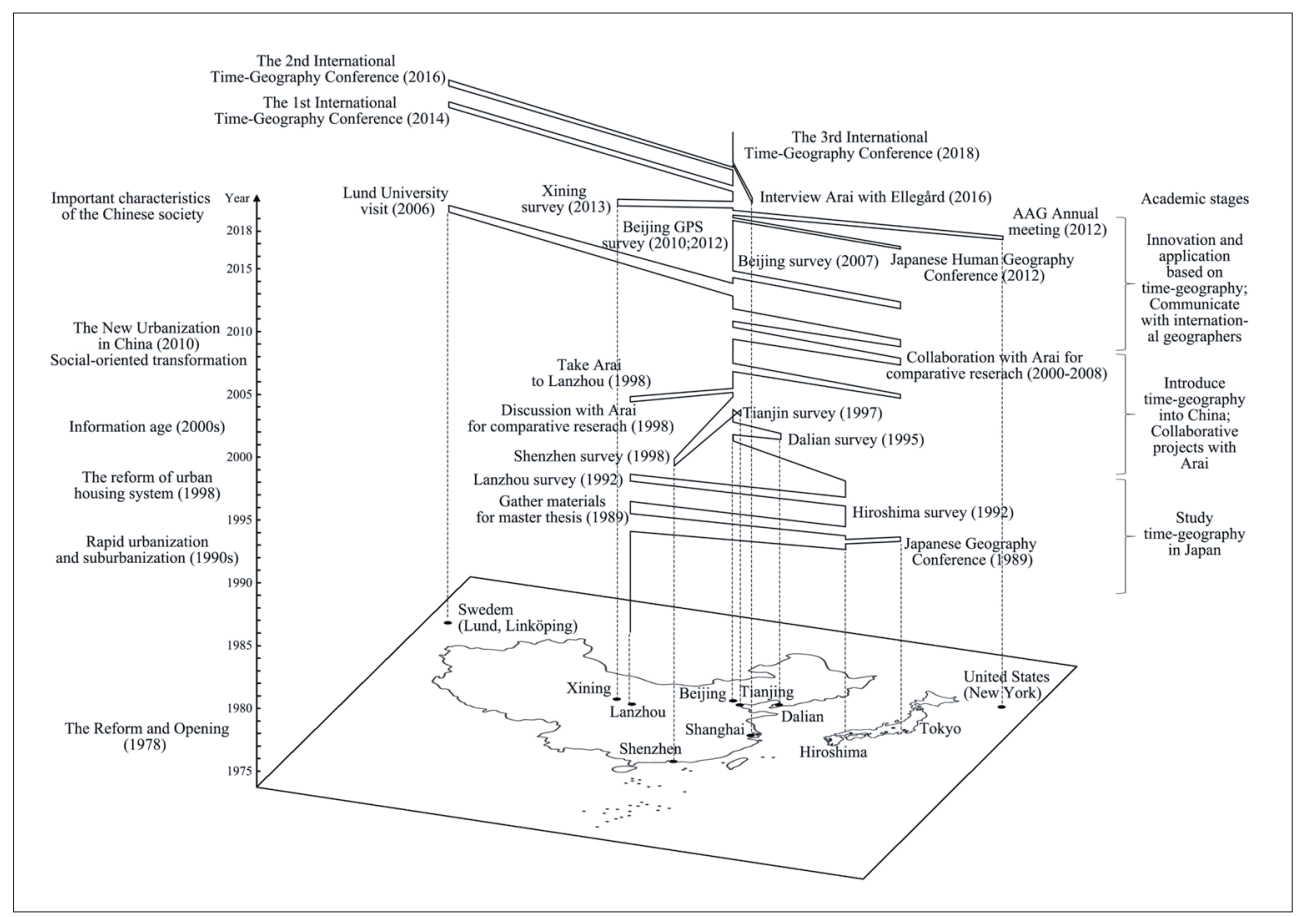

Fig. 5: Important characteristics of the Chinese society, the individual life path showing the locations and years of Chai's geographical movements and main academic activities, and the academic stages of Chai

Source: authors' elaboration

Chai first saw the term "time-geography" in the graduate entrance examination in Human Geography at Hiroshima University in 1989. The exam asked students to explain each term; however, Chai did not know what time-geography meant at that moment. On the other hand, this shows that timegeography was known well enough by Japanese geographers.

After that, Chai learned about time-geography by reading published papers and books and by attending presentations, especially by the Time-Geography Study Group. The first time-geographic article read by Chai was the review and research of fisherman's daily activity by Kushiya (1985a, 1985b). The first time-geographic research presentation heard by Chai was the time-geography session organised by Arai and other group members in the Japan Geography Conference in 1989. The first time-geographic book studied by Chai was "Space of Life Time in City" (Arai et al., 1989). Although Chai thus first studied timegeography because of the introductory work of the TimeGeography Study Group, he seldom thought of using it in his academic research.

\subsection{Preliminary application of time-geography during his graduate studies}

The title of Chai's undergraduate thesis is "Research on Agriculture Geography in Qinhai Province" in China. Although he had a solid base in physical geography, Chai insisted on doing human geography research when he was facing the challenge of his master's thesis. Therefore, Chai chose urban spatial structure in Lanzhou as his research topic. In order to innovate, Chai's study analysed not only the structure of land use, but also the structure of residents' daily activity, i.e. the urban activity space.

He returned to Lanzhou in 1989 and gathered materials for research. During his research, Chai realised that danwei compounds play an important role in Chinese urban space. Danwei was the generic term indicating Chinese socialist workplaces. It provided employees not only with jobs, but also residence and a bunch of daily services within its own realm (Bray, 2005). Therefore, danwei was the basic living space for Chinese urban residents, and more importantly, Chinese cities were organised based on danwei. Influenced by Japanese geographers, Chai used the concept of "life circle" and time-geography to describe and analyse the role of danwei in the organisation of residents' daily lives. Two of his articles were published (Chai, 1991, 1993), which greatly improved Japanese scholars' understanding of Chinese cities.

After completing his master's degree, Chai proposed a framework of a comparative study between Chinese and Japanese cities for his doctoral project. Time-geography was used to analyse daily activity in both countries. Chai, however, did not know how to design the questionnaire and collect activity data. Fortunately, Arai sent him the daily activity questionnaire used in the Shimosuwa survey (Fig. 2) to help fix the problem.

Chai conducted his activity diary surveys in both Hiroshima and Lanzhou, with a sample of 400 households and 800 diaries (half workdays, half weekends) in 1992. Two articles about the activity space of residents in both cities were published (Chai, 1993, 1994). Chai's doctoral thesis, which compared the land use and activity space structures of Hiroshima and Lanzhou, was published in Japanese as well as Chinese (Chai, 1999). The methods Chai used in his several time-geographic studies to analyse and visualise residents' daily activities were highly influenced by the papers published by the Time-Geography Study Group. Taking the visualisation of individual paths as an example (see Fig. 6), we can easily find similarities between Kamiya et al. (1990) and Chai (1999).

\subsection{Introduction and application of time-geography in China}

Chai returned to China after completing his doctorate in 1994. He became a post-doctoral student and further an Associate Professor at Peking University. During the 


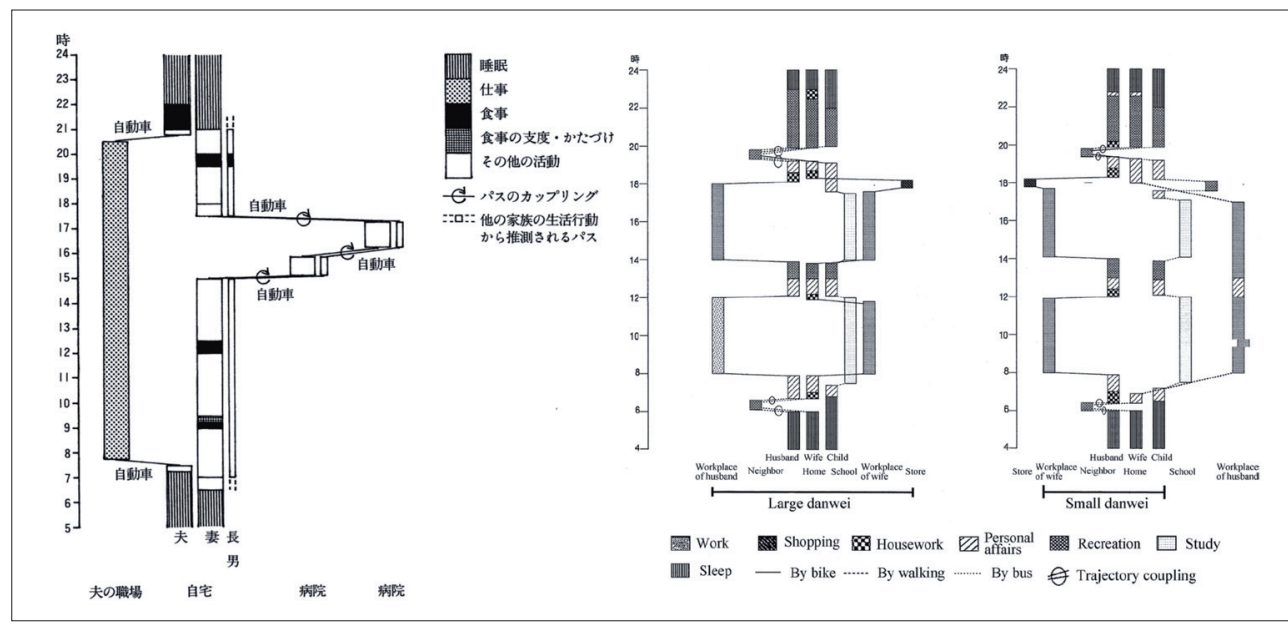

Fig. 6: Daily activity paths of family members illustrated in Kamiya et al., 1990 (left) and Chai, 1999 (right)

period 1994-2000, he undertook four research projects, which concerned the application of time-geography in urban spatial structure, travel behaviour and urban planning studies. Besides, Chai and his research team published some introductory papers, including basic concepts and the methodology of time-geography, and reviews of timegeographic research in other countries (Chai and Wang, 1997; Chai, 1998; Chai et al., 2000; Chai and Gong, 2000; Chai et al., 1999). These papers, for the first time in China, introduced time-geography and an individual-based research perspective and methodology. Three activity diary surveys were conducted in Dalian (1995), Tianjin (1997) and Shenzhen (1998) by his research group. A series of articles were published, which were then selected and published as "Spatio-Temporal Structure of Chinese Cities" (Chai et al., 2002). The key idea of these papers was to understand urban spatial structures from the perspective of individual activities.

A comparative study of residents' daily activities in Japanese and Chinese cities, in collaboration with Arai, was conducted from 2000 to 2008. More detailed information about this cooperative work is discussed in Section 4, below. Although the results of this comparative study contributed to the understanding of both Japanese and Chinese cities, Chai thought that the analytic methods lacked innovation. The methods used in most of the research consisted of aggregating daily activity data and illustrating it in figures and tables, or just visualising individual daily activity paths. The reasons behind the activity patterns were mainly inferred from interviews. Few quantitative methods were used to test the hypotheses. Therefore, he turned to research based on the theory and methodology of behavioural geography.

Chai received research funding from the Natural Science Foundation of China (NSFC) for work on behavioural geography in 2002, and a series of articles about consumer behaviour was published, including space-time characteristics, influencing factors and decision-making processes. Chai was regarded as the leader of Chinese behavioural geography at that time. Related research was summarised and published as "Urban Space and Consumer Behaviour" (Chai and Zhang, 2010). In addition, the daily behaviour of the elderly was also studied in this period. The results were published in "Activity Space of the Urban Elderly in China" (Chai, 2010). Behavioural geography research is hard to continue, however, because it lacks theoretical foundation and is usually regarded as merely mathematical models. There had not been substantial progress in global behavioural geography for some time after
Reginald Golledge's work. Besides, mixed methods research (the combination of qualitative and quantitative research) was gaining much attention at that time. Therefore, Chai decided to turn back to time-geography.

\subsection{Methodological innovations and urban planning applications based on time-geography}

The first challenge taken on by Chai was to think further about the previous time-geographic research paradigm. The quantitative analytical perspective and methods in behavioural geography research provided an important basis for innovation. Chai and his research group tried to reflect the socio-spatial reconstruction happening in Chinese cities by investigating the interaction between space and behaviour. Time-geography emphasises the influence of societal and technological change on human behaviour. By analysing the influencing factors of behaviour, we can understand urban transitions, such as housing system reform and suburbanisation, from a behavioural perspective. Based on this perspective, Chai proposed a new research framework and received another grant from the NSFC in 2007.

A new activity diary survey in Beijing was conducted in 2007. Despite similar questionnaires, new analytical frameworks and tools were employed. Many articles using this dataset were published, and one of the most influential works was on the effects of danwei on residents' space-time behaviour patterns, such as home-work relationships, travel behaviour, trip rates and time spent on out-of-home activities (Wang et al., 2011; Wang and Chai, 2009). Suburbanisation was also found to have a great influence on travel behaviour, activity spaces and out-of-home non-work activities (Ta et al., 2016; Ta et al., 2015; Shen et al., 2015; Shen and Chai, 2013). The results based on this new dataset were published in "Spatial Behaviour and Behavioural Space" (Chai, 2014a). Moreover, the change in activity patterns was due to urban transformation; meanwhile, behavioural change could affect environmental sustainability and the quality of life. Hence, recent trends were observed in sociospatial segregation (Zhang et al., 2018; Wang et al., 2012), environmental pollution (Ma et al., 2015; Liu et al., 2017) and health geography (Ma et al., 2020; Ma et al., 2017) from the perspective of space-time behaviour.

Another innovation was implementing different data collection methods. Learning from space-time behaviour research in Western countries, Chai and his research team started integrating GPS and mobile telephone tracking 
technologies into classical activity diaries to collect more accurate and real-time activity information. A pilot survey with a sample of 100 individuals was conducted in Beijing in 2010 with the support of the IBM Company. Participants were asked to carry a mobile tracking device with built-in GPS and mobile telephone chips over a week and to complete activity diaries through an online survey platform (Chai et al., 2013; Huang et al., 2010). Another survey using the same data collection method with 709 respondents was conducted in the Shangdi-Qinghe area in Beijing in 2012, under the auspices of the National Science and Technology Support Program (NSTSP). Guided by the uncertain geographic context problem (UGCoP) proposed by Kwan (2012), portable air pollution and noise sensors were furtherly integrated with GPS and activity diaries during data collection, to avoid contextual uncertainties in health and social science research (Kwan, 2018). The research teams of Chai and Mei-Po Kwan conducted surveys using the same data collection method in both Beijing and Chicago, under a China-US joint research project supported by the NSFC. Accompanied by innovations in the data collection method, Chai also made progress in analytical methods: GIS-based disaggregate-level methods were developed to visualise and analyse real-time high-resolution space-time behaviour data (Chen et al., 2011; Shen et al., 2013).

Applying space-time behaviour research to urban planning and governance was another innovation Chai and his research team made during these years. Based on the collection and analysis of behavioural data, Chai established a smart travel planning framework and accomplished a demonstration project in the Shangdi-Qinghe area supported by NSTSP (Chai and Chen, 2018). On the one hand, by acquiring, visualising and analysing individual travel data and real-time position, related agents could provide personalised travel information to support travel decisions and realised travel planning. On the other hand, by analysing and simulating aggregated travel patterns and needs, the government could adjust and optimise traffic infrastructure and service systems (Chai et al., 2014). Another application of time-geography and the space-time behaviour approach was to life circle planning. Life circle, the concept borrowed from Japanese geographers, has had a great influence on Chai's academic life. In early research, Chai found that danwei is the primary unit of Chinese urban society and can be seen as a daily life circle (Chai, 1996). Although the danwei system collapsed after the housing system reform, its initial aim to fulfil the basic needs of residents' daily behaviour is still valuable for today's planning practice (Liu and Chai, 2015). Chai's research team proposed the theoretical urban life circle planning framework and then tried to integrate it into the current planning system (Chai et al., 2015; Sun et al., 2016). One of the projects was to optimise the supply of public infrastructure based on the concept of community life circles, which was cooperative work with the Beijing Municipal Institute of City Planning \& Design (Sun and Chai, 2017).

In addition to innovations and applications based on timegeography, Chai continued his pioneering work on timegeography in China. Two important special issues were organised by Chai in Chinese journals of geography and urban planning. The first is "Time-Geography and Urban Planning" published in "International Urban Planning" in 2010, which introduces international research advances on GIS methods in time-geography, as well as some theoretical thinking about a combination of time-geography and Chinese urban planning (Chai et al., 2010). The other special issue aimed at introducing recent advances of a theoretical nature and the application of time-geography and space-time behavioural research, which was published in "Progress in Geography" in 2013 (Chai and Ta, 2013). The "Frontier of Space-Time Behaviour Research", edited by Chai, was also published in 2014, which summarised theoretical, methodological and application-related progress in space-time behavioural research (Chai, 2014b). Meanwhile, Chai extended his research network during this period. The Urban China Spatial-Temporal Behaviour Research Network (UCSB) was established, and several international exchange and cooperation activities were conducted with top researchers in this field, such as Mei-Po Kwan, Shih-Lung Shaw, Harvey Miller, Martin Dijst, Tim Schwanen and Rein Ahas.

\subsection{Recent trends: Towards a "new" time-geography}

After attending time-geography sessions at the AAG Annual Meeting in 2012 and participating in the first and second International Time-Geography Conference in Sweden in 2014 and 2016, respectively, Chai decided to apply to an exchange and cooperation project with Swedish timegeographers in order to promote theoretical innovation in China. Kajsa Ellegård from Linköping University, Sweden, and Chai jointly applied for this grant, which was co-funded by the NSFC and Swedish Foundation for International Cooperation in Research and Higher Education (STINT). Research groups from both sides were exchanged each year from 2014 to 2018 by organising seminars, giving lectures and teaching. The $3^{\text {rd }}$ International Time-Geography Conference was also held at Peking University during this period.

The achievements of this project are surprising. Chai and his research group refreshed their understanding of time-geography, which is called the "new" time-geography in Chinese. The concepts of 'project' and 'pockets' of local order (POLO) and other undiscovered knowledge of timegeography have been gradually understood since then. Recent progress made by Swedish time-geographers also came into view for the first time. Related introductory articles were published by Chai and Ellegård in a special issue of "Human Geography" in Chinese (Zhang and Chai, 2016).

Currently, Chai and his research team have completed the introductory work on the "new" time-geography by articles and lectures across China. They are now undertaking empirical research based on the new knowledge they have learned. A series of articles and a Chinese time-geographic textbook will be published in the near future.

\section{Interaction between and comparison of academic life paths}

\subsection{Summary of key events and interactions}

Yoshio Arai and Yanwei Chai have played an important role in the diffusion and development of time-geography in Japan and China, which can be concluded from their academic life paths. Moreover, there exist some key events during this process, and most of the key events are interactions between Arai and Chai, which considerably help promote timegeography in their countries. In chronological order, the key events and interactions are shown in Figure 7 and are also summarised and analysed below.

\subsubsection{Interactions during Chai's studies in Japan}

The establishment of the Time-Geography Study Group and the publication of the anthology of time-geographic classic articles by Arai and other scholars, can be regarded as iconic 


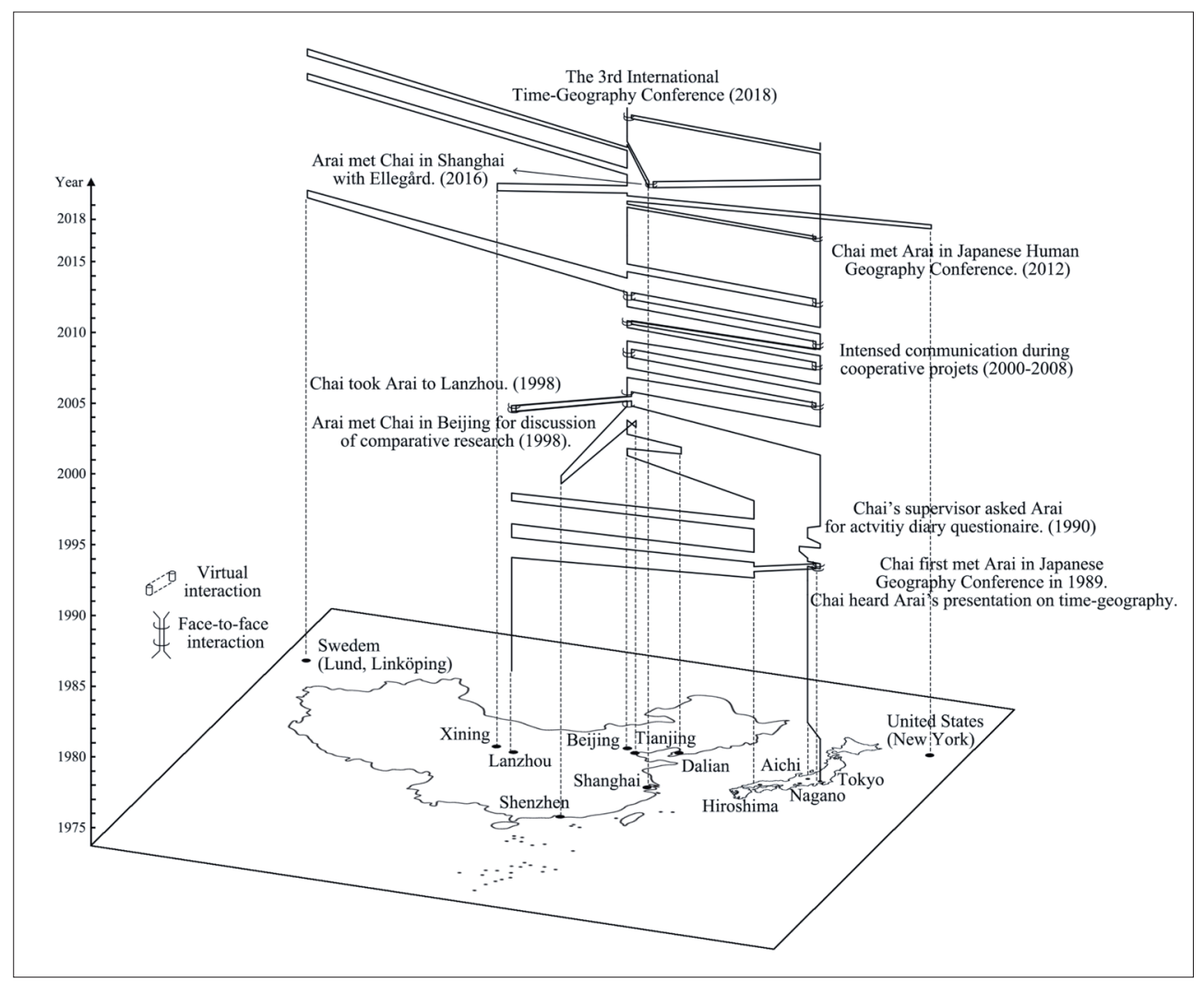

Fig. 7: Interactions (virtual and face-to-face) of the academic life paths of Arai and Chai Source: authors' elaboration

events that promoted the diffusion of time-geography in Japan. Their empirical studies developed time-geography in Japan and enabled Japanese scholars to better understand the daily activity and quality of life of urban residents. In 1989, Arai and other group members participated in the annual Japanese Geography Conference in Tokyo. It was at that time that Chai met Arai for the first time and heard his first presentation on time-geography. Chai was impressed by Arai's speech and decided to learn time-geography through the works of the Time-Geography Study Group. The anthology provided a good start for him to learn time-geography systematically.

Arai further provided help during Chai's empirical study. When Chai was going to conduct his own activity diary surveys in Lanzhou and Hiroshima, Arai provided the questionnaire used in the Shimosuwa, Nissin and Kawagoe surveys. The same questionnaire and the data collection method they used also helped their joint comparative study in the next stage. Moreover, Chai learned much about the research ideas, analytical methods and visualisation techniques from the empirical studies conducted by Arai and his Time-Geography Study Group members. These interactions, though virtual in some cases, strongly influenced Chai's academic life and brought time geography into China indirectly. We could see this influence continue with Chai's earlier research, which provided a unique behavioural perspective for Chinese urban geographers to understand urban spatial structure. In his introductory works of time-geography to China, Chai also directly referred to the translation and definition of some important concepts by Japanese geographers, such as activity space.

\subsubsection{Interactions during the joint comparative study}

After Chai returned to China, the most important interaction between these two scholars was the joint comparative study. In 1998, Arai had the opportunity to visit Chai in Beijing. Chai showed Arai around Beijing and took him to Lanzhou for a visit, where Chai had conducted an activity diary survey in 1992. This visit aroused Arai's interest in Chinese cities. Therefore, Arai and Chai planned the joint study, which aimed to compare cities in Japan and China based on the activity data collected by previous surveys conducted by them. The survey data could be compared easily because the Japanese and Chinese surveys used similar questionnaires.

The comparative analyses were conducted between 2000 and 2005 with support from the Japanese Government's Grants-in-Aid. The Japanese members were Yuko Tahara from Kokugakuin University, Kohei Okamoto and Arai. In addition, graduate students from the University of Tokyo and Nagoya University also joined the Japanese team. In China, the "Study Group on Behavioural Geography at Peking University" joined the collaboration. The research topics included urban activity systems, activity space and the welfare of disadvantaged groups, and adjustments in household employment and housework activities. A special issue was published in "Komaba Studies in Human Geography" in 2003 (Arai, 2003; Okamoto, 2003; Chai and Liu, 2003; Tahara, 2003; Nishimura, 2003). In 2008, the results from this comparative study were published as a Japanese book, "Activity Space in Chinese Cities" (Arai et al., 2008).

The comparative study helps promote understanding of both Chinese and Japanese cities. Through comparison, the reasons why Japanese families were facing serious childcare problems have been elucidated, and the misguided attitude that women must quit full-time jobs for child rearing has been changed. In terms of China, the role danwei plays in urban life had been emphasised again. 


\subsubsection{Interactions after the comparative study}

Most interactions occurred between Arai and Chai via virtual means after the collaborative project; however, Chai still met Arai and other members of the Time-Geography Study Group on occasion. In 2012, Chai went to Japan to attend the annual Japanese Human Geography Conference. Chai talked with Arai and realised that he had changed his research interest, partly because it was hard to conduct GPS surveys or collect mobile telephone data due to privacy concerns, although it was at the frontier in time-geography and behavioural research at that time. After a discussion with Arai and Okamoto, however, Chai decided to stick to time-geography and started a new GPS survey in Beijing. The reason that Chai continued to follow the new trend in time-geography was that China was just entering the socialoriented transformation stage after the government released the "New Urbanisation" policy in 2010. Society needed individual-based research and behavioural research in order to improve the quality of life. At the same time, Japanese society started social transformation early in the 1970s and it was facing new problems. Moreover, there were few new generations of time-geographers in Japan. Yuichiro Nishimura from Nara Women's University is probably the only one after the generation of Arai and Okamoto. He tried some new techniques such as GPS and GIS in his early research (Nishimura et al., 2008), but the survey was conducted in Laos, and it was hard for him alone to continue such research in Japan.

In 2016, Arai met Chai and Ellegård in Shanghai. Ellegård was working on her project aimed at an overview of time-geography and its development, diffusion and future, through meetings and interviews with international researchers at that time. Chai helped Ellegård's interview with Arai and Okamoto, and they also wrote a chapter in the book edited by Ellegård, "Time-Geography in the Global Context", to summarise time-geographic research in Japan (Okamoto and Arai, 2018). At the $3^{\text {rd }}$ International TimeGeography Conference held at Peking University, Chai and Arai had another chance to meet again, and they introduced the development of time-geography in their countries separately. In addition, after several years of innovation and the refreshment of time-geography, it is Chai that continues to give lectures on advances in space-time behavioural research and their applications, as well as the "new" timegeography in Japan.

\subsection{Comparison of academic life paths}

Similarities and differences exist between the academic life paths of Arai and Chai. Both scholars knew and learned time-geography from published articles and books. Both research groups shared common research topics which applied time-geographic theory and methods to urban issues. For example, Arai and his group applied time-geography in urban life and clearly demonstrated factors influencing the quality of life of women and the elderly. Chai and his team analysed residents' daily activities based on timegeography, to reflect urban spatial structure and the huge socioeconomic transition occurring in Chinese mega-cities. In addition, Chai also attempted to apply time-geography and space-time behavioural research in urban planning and governance practices, such as life circle planning and smart travel planning.

The socioeconomic context (with respect to broader country conditions) of their academic life is also quite similar (see Fig. 8). When Arai and other members of the Time-Geography Study Group decided to systematically learn and use time-geography in the 1980s, the urbanisation level of Japan was very high (76.7\% in 1985). Quality rather than quantity was the emphasis in the next urbanisation stage. Meanwhile, Japanese society was facing problems of an aging population, gender inequality and declining birth rates. Therefore, time-geography provided a unique tool to analyse individual daily lives, especially of the aged and female groups, in order to improve their quality of life (Sugiura, 2005; Yui et al., 2004; Yui, 2012). For Chai, although the urbanisation level of China was not high when he returned, the urbanisation level of Chinese mega-cities was high. For example, the urbanisation level of Beijing in 1995 was $75.6 \%$. In addition, if we look at the innovative and influential work by Chai from 2007 to 2014, the

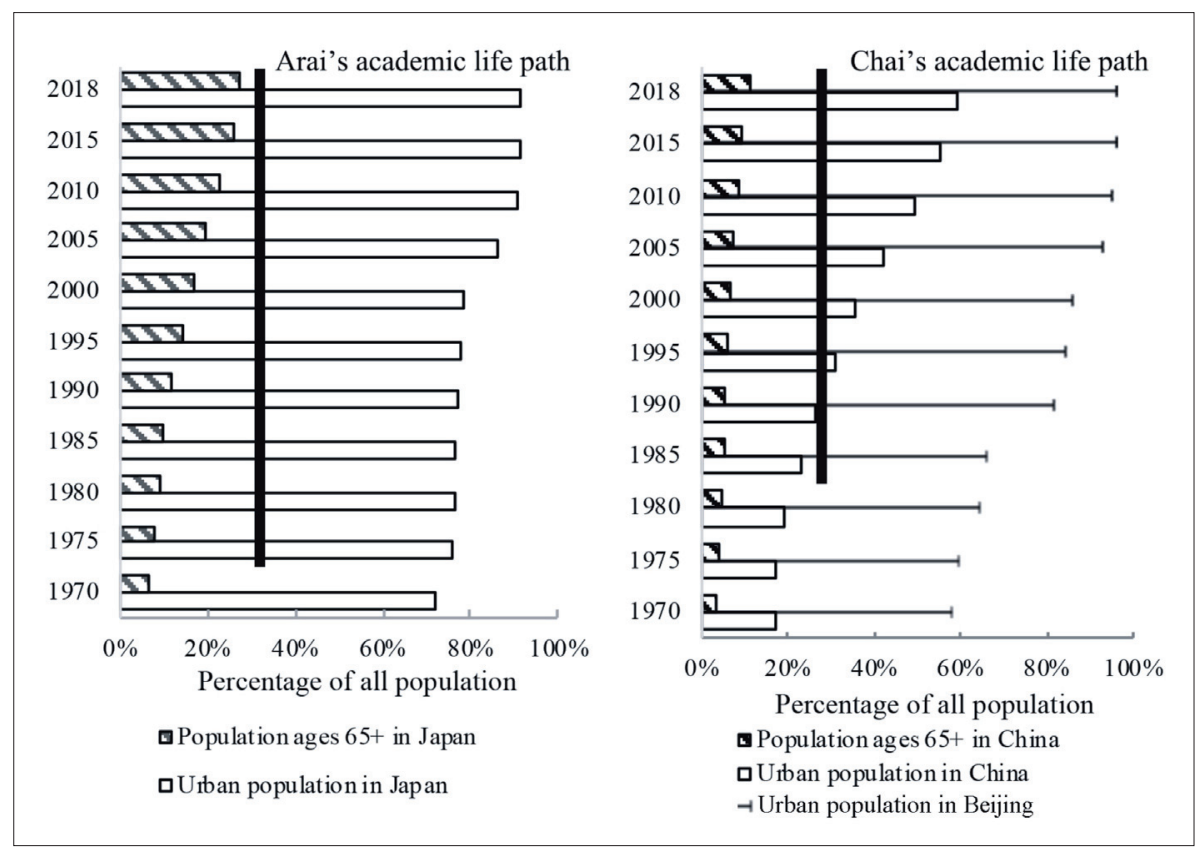

Fig. 8: Socio-economic backgrounds of academic life paths of Arai and Chai

Source: authors' elaboration 
urbanisation level across all of China was also 50\%, which means it was entering a quality-first stage. Besides, Chinese society faces similar problems, such as population aging and social inequality. In fact, similar problems arising from rapid urbanisation and large-city growth were also faced by Torsten Hägerstrand, when he put forward time-geography in Sweden (Ellegård, 2018b; Pred, 1973). Therefore, this similar socioeconomic background indicates that the academic life paths of Arai and Chai are tightly related to societal context.

There are also differences between their life paths. Arai has switched his research interest to ICTs and daily life since the mid-2000s, while Chai has continued his time-geography research until the present. Although Arai and his colleagues have accomplished valuable work, few English papers have been published, and they seldom communicate with other researchers, especially those from Western countries. In contrast, Chai has extended his research network with top researchers in this area internationally, which promotes his innovations directly.

\section{Discussion and conclusion}

This article has provided an overview of the diffusion and development of time-geography in East Asia. Specifically, it summarised how time-geography was introduced and promoted in Japan and China from the perspectives of the academic life paths of Yoshio Arai and Yanwei Chai. The life path analysis is employed because these two scholars have played an important role during this process. The development of time-geography in both countries goes hand in hand with the academic progress made by them. Moreover, there are some interactions between their academic life paths, which mark some key events that promoted time-geography significantly. Finally, this article analysed the similarities and differences between their academic life paths. Both scholars learned time-geography through published English or Japanese articles on time-geography, and they also shared some common research topics in the early stages. In addition, the socioeconomic backgrounds of their academic life paths are quite similar. There are still some differences, however, including their recent research interests and international communications.

Firstly, the academic life path method is demonstrated in this article to be a useful tool to depict the intellectual history of a certain discipline and to analyse the role of key individuals in this process. Compared with conventional literature reviews, the academic life path method provides a clearer trajectory and more vivid information on how the discipline develops. The time, place and contents of the important academic events are clearly visualised on the path, as well as the socioeconomic background and the academic stages. The importance of key individuals and their interactions are also highlighted by this method. Besides, the path can be described at different temporal scales depending on research objectives. For example, we can focus on the joint comparative study and depict the interactions between Arai and Chai during the period 2000-2008 in detail, if we want to analyse how the joint study was completed and its influence on Japanese and Chinese academies and societies. A broader overall view of the development of the discipline cannot be shown by this method, however, and that is the strength of a systematic literature review.

Secondly, the application of the academic life path method in studying the diffusion and development history of timegeography provides a good scheme for other disciplines.
Most modern disciplines, especially in the social sciences, share similar diffusion and development patterns and characteristics with time-geography. They tend to have originated from Europe, and then diffused firstly into other Western countries, such as United States, and secondly into East Asia. In addition, like time-geography, the most prominent characteristics of the disciplines in East Asia are the innovative applications in some new research topics, which tightly relate to societal problems. Therefore, the life path method can be applied to learn the developmental trajectory of other disciplines and to understand the role of key scholars, in the important socioeconomic context of any comparative country analysis.

Finally, the diffusion process of time-geography in Japan and China is clearly visualised by these two scholars' academic life paths. Furthermore, the analysis of socioeconomic backgrounds of their paths reveals some mechanisms behind the diffusion and development of timegeography. Both scholars introduced and applied timegeography when societal-oriented transformations happened in cities. At that time, urbanisation rates were above $50 \%$ and it was quality rather than quantity that urban development focused upon. Human-based urban planning was proposed, which called for individual-based research to improve life satisfaction and the quality of life. Therefore, time-geography provided a novel and useful theory and method for these studies. The socioeconomic backgrounds faced by Arai and Chai also coincide to some extent with the context when Hägerstrand proposed time-geography in Sweden in 1970 (Hägerstrand, 1970; Ellegård, 2018b). And time-geography was soon applied in facilities adjustment, time allocations and travel requirements by his colleagues and students (Ellegírd et al., 1977; Lenntorp, 1970). Hence, it can be concluded that the development of time-geography is tightly related to the socioeconomic context and promoted by practical demands. It can also be inferred that time-geography may be diffused to other developing countries, which are currently facing rapid urbanisation, such as India.

After spatial construction has entered a steady mode due to low levels of urban population growth and low birth rates, social construction becomes the major challenge in developed countries. Accordingly, time-geography has also developed in response to societal needs. In Sweden, timegeography has been applied to sustainable development, energy consumption and the impacts of ICTs in everyday life (Ellegård and Palm, 2015; Thulin and Vilhelmson, 2012). In the US, new research directions based on timegeography are sustainability, social segregation and health (Kwan, 2013; Park and Kwan, 2018; Song et al., 2017). In China, though still under the process of spatial construction, time-geography has been applied in the research of social differentiation, environmental exposure and health ( $\mathrm{Ma}$ et al., 2020; Zhang et al., 2019). Hence, new trends in Sweden and the US were also introduced in China. In terms of Japan, Okamoto is currently studying daily activities and evacuation behaviours for natural disaster effects reduction based on time-geography. Except for his studies, there are few papers regarding this new social transformation, probably because of the lack of scholars as well as privacy concerns with respect to data collection.

In conclusion, this article finds that the diffusion of timegeography from the West to the East cannot happen without the hard work of some key scholars and their research teams. Early published English articles on time-geography are also quite important for the scholars in Japan and China, for 
they helped researchers from all over the world to overcome geographical distance and know recent academic progress in the 1970s and 1980s, when there was no Internet. International cooperation also plays an important role during this process. Friendships among these researchers are created and deepened alongside exchange and cooperation activities, as time-geography is also developed because of their long-lasting relationships.

The $3^{\text {rd }}$ International Time-Geography Conference held in Peking University in 2018 can be regarded as an indication that time-geography in East Asia has entered the international stage. In the next step, it is important for Asian time-geographers to strengthen exchange and cooperation activities and build international research networks. The annual China-Japan-Korea Joint Conference on Geography and the Asian Geography Conference can also be good opportunities for time-geographers to gather and communicate. The recent increase in international collaborative research and projects can also help promote this interaction. Moreover, time-geography in East Asia should go beyond application - to the innovation of theory and method. We should contribute to global time-geography with our characteristic Asian experiences.

\section{Acknowledgements}

This research was funded by National Natural Science Foundation of China (41571144; 41529101).

\section{References:}

ARAI, Y. (2003): On Human Activities in Chinese and Japanese Cities: A Comparative Study. Komaba Studies in Human Geography. 16: 1-39. (In Japanese)

ARAI, Y., KAWAGUCHI, T., OKAMOTO, K., KAMIYA, H. (1989): Space of Life Time in City: Anthology of TimeGeography. Tokyo, Kokon-Shoin. (In Japanese)

ARAI, Y., NAGANUMA, S., SATAKE, Y. (2012): Local government broadband policies for areas with limited Internet access. An analysis based on survey data from Japan. Netcom, 26(3/4): 251-274.

ARAI, Y., OKAMOTO, K., KAMIYA, H., KAWAGUCHI, T. (1996): Space and Time in the City: Time-geographic Study on Daily Activities. Tokyo, Kokon Shoin. (In Japanese)

ARAI, Y., OKAMOTO, K., TAHARA, Y. AND CHAI, Y. (2008): Activity Space in Chinese Cities: Social Structure, Gender, Elders. Kyoto, Nakanishiya Shuppan. (In Japanese)

BRAY, D. (2005): Social space and governance in urban China: The danwei system from origins to reform. Stanford University Press.

CHAI Y., LIU Z. (2003): The Transformation of Work Unit System in China: Its Implication to Individual Daily Life and Urban Spatial Restructuring. Komaba Studies in Human Geography. 16: 55-78. (In Japanese)

CHAI, Y. (1991): Urban internal structure of China's cities: a case study of Lanzhou City. Japanese Journal of Human Geography, 43(6): 526-545. (In Japanese)

CHAI, Y. (1993): Daily life activity space of Hiroshima citizens: a case study of citizens in their forties. Japanese Journal of Human Geography, 45(4): 351-373. (In Japanese)

CHAI, Y. (1993): Urban internal structure and residents' life in China's cities. Annual report of the Urban Society of Japan (27): 9-12. (In Japanese)
CHAI, Y. (1994): Daily-Life Activity Space of Chinese Citizens - A Case Study of Lanzhou City. Geographical Sciences, 49(1): 1-24. (In Japanese)

CHAI, Y. (1999): A Comparative Study on the Urban Internal Spatial Structure between Chinese Cities and Japanese Cities. Beijing, Peking University Press. (In Chinese)

CHAI, Y. (2010): Activity Space of the Urban Elderly in China. Beijing, Science Press. (In Chinese)

CHAI, Y. (2013): Space-Time Behaviour Research in China: Recent Development and Future Prospect. Annals of the Association of American Geographers, 103(5): 10931099. doi:10.1080/00045608.2013.792179

CHAI, Y. (2014a): Spatial Behaviour and Behavioural Space. Nanjing, Southeast University Press. (In Chinese)

CHAI, Y. [ed.] (2014b): The Frontier of Space-Time Behaviour Research. Nanjing, Southeast University Press. (In Chinese)

CHAI, Y., CHEN, Z. (2018): Towards mobility turn in urban planning: Smart travel planning based on space-time behaviour in Beijing, China. In: Shen, Z., Li, M. [eds.]: Big Data Support of Urban Planning and Management (pp. 319-337). Berlin, Springer.

CHAI, Y., LIU Z., LI Z., GONG H., SHI Z., WU Z. (2002): Spatio-temporal structure of Chinese cities. Beijing, Peking University Press. (In Chinese)

CHAI, Y., LIU, Z., ZHANG, Y. (2015): Space-time behaviour research and application in China. In: Kwan, M.-P., Richardson, D. Wang, D., Zhou, C. [eds.]: Space-Time Integration in Geography and GIScience (pp. 21-38). Berlin, Springer.

CHAI, Y., TA, N., MA, J. (2016): The socio-spatial dimension of behaviour analysis: Frontiers and progress in Chinese behavioural geography. Journal of Geographical Sciences, 26(8): 1243-1260. doi:10.1007/s11442-016-1324-x

CHAI, Y., ZHANG H. (2010): Urban Space and Consumer Activity. Nanjing, Southeast University Press. (In Chinese)

CHEN, J., SHAW, S.-L., YU, H., LU, F., CHAI, Y., JIA, Q. (2011): Exploratory data analysis of activity diary data: A space-time GIS approach. Journal of Transport Geography, 19(3): 394-404.

ECONOMIC PLANNING AGENCY (1987): Time and Consumption. Tokyo, Okurasho Insatsu Kyoku. (In Japanese)

ELLEGÅRD，K., HÄGERSTRAND，T., LENNTORP，B. (1977): Activity organization and the generation of daily travel: two future alternatives. Economic Geography, 53(2): 126-152.

ELLEGÅRD, K. (1999): A time-geographical approach to the study of everyday life of individuals - a challenge of complexity. GeoJournal, 48(3): 167-175.

ELLEGÅRD, K. (2018b): Thinking time geography: Concepts, methods and applications. London, Routledge.

ELLEGÅRD, K., PALM, J. (2015): Who is behaving? Consequences for energy policy of concept confusion. Energies, 8(8): 7618-7637.

ELLEGÅRD, K., SVEDIN, U. (2012): Torsten Hägerstrand's time-geography as the cradle of the activity approach in transport geography. Journal of Transport Geography, 23: $17-25$. 
ELLEGÅRD, K., VILHELMSON, B. (2004): Home as a pocket of local order: everyday activities and the friction of distance. Geografiska Annaler: Series B, Human Geography, 86(4): 281-296.

ELLEGÅRD. K. [ed.] (2018a): Time Geography in the Global Context. London, Routledge.

HÄGERSTRAND, T. (1970): What about people in regional science? Papers in Regional Science, 24(1): 6-21.

HÄGERSTRAND, T. (1975): Space, time and human conditions. In: Karlqvist, A., Lundqvist, L., Snickars, F. [eds.]: Dynamic allocation of urban space. Saxon House.

HÄGERSTRAND, T. (1982): Diorama, path and project Tijdschrift Voor Economische En Sociale Geografie, 73(6): 323-339.

HUANG, A., MA, X., CHAI, Y., LIU, Y., LI, Y. (2010): Individual activity data collection based on mobile positioning infrastructure in Beijing. In $201018^{\text {th }}$ International Conference on Geoinformatics (pp. 1-6]. Beijing, IEEE.

ISHIMIZU T. (1976): An Outline of Quantitative Geography. Tokyo, Kokon Shoin. (In Japanese)

JONES, P., DIX, M. C., CLARKE, M. I. (1987): Understanding travel behaviour. Brookfield, Vt., Gower.

KAMIYA, H., OKAMOTO, K., ARAI, Y., KAWAGUCHI, T. (1990): A time-geographic analysis of married women's participation in the labor market in Shimosuwa town, Nagano prefecture. Geographical Review of Japan, 63(11): 766-783. (In Japanese)

KUKIMOTO, M. (2016): Geography of Childcare and Parenting Support. Tokyo: Akashi Shoten. (In Japanese)

KUSHIYA, K. (1985a): Time-geographic interpretation of fisherman's daily activity on Tokyo Bay, Japan. Geographical Review of Japan, (58): 645-662. (In Japanese)

KUSHIYA, K. (1985b): Time-geographic Studies: A Review. Japanese Journal of Human Geography, 37(6): 533-551. (In Japanese)

KWAN, M.P. (2012): The uncertain geographic context problem. Annals of the Association of American Geographers, 102(5): 958-968.

KWAN, M. P. (2013): Beyond space (as we knew it): Toward temporally integrated geographies of segregation, health, and accessibility: Space-time integration in geography and GIScience. Annals of the Association of American Geographers, 103(5): 1078-1086.

KWAN, M. P. (2018): The Limits of the Neighborhood Effect: Contextual Uncertainties in Geographic, Environmental Health, and Social Science Research. Annals of the American Association of Geographers, 108(6): 1482-1490.

KWAN, M. P., WEBER, J. (2003): Individual accessibility revisited: Implications for geographical analysis in the twenty-first century. Geographical Analysis, 35(4): 341-353.

LENNTORP, B. (1970): PESASP - en modell för beräkning av alternativa banor. Institutionen för kulturgeografi och ekonomisk geografi vid Lunds universitet [A]. Serie: Urbaniseringsprocessen, 38.

LENNTORP, B. (1976): Paths in space-time environments: A time-geographic study of movement possibilities of individuals. Lund Studies in Geography Series B: Human Geography (44). Lund, Royal University of Lund.
LENNTORP, B. (2004): Path, prism, project, pocket and population: an introduction. Geografiska Annaler: Series B, Human Geography, 86(4): 223-226.

LIU, T., CHAI, Y. (2015): Daily life circle reconstruction: A scheme for sustainable development in urban China. Habitat International, 50: 250-260.

LIU, Z., MA, J., CHAI, Y. (2017): Neighborhood-scale urban form, travel behaviour, and $\mathrm{CO}_{2}$ emissions in Beijing: implications for low-carbon urban planning. Urban Geography, 38(3): 381-400.

MA, J., LI, C., KWAN, M. P., KOU, L., CHAI, Y. (2020): Assessing personal noise exposure and its relationship with mental health in Beijing based on individuals' spacetime behaviour. Environment International, 139, 105737.

MA, J., LIU, Z., CHAI, Y. (2015): The impact of urban form on $\mathrm{CO}_{2}$ emission from work and non-work trips: The case of Beijing, China. Habitat International, 47: 1-10.

MA, J., MITCHELL, G., DONG, G., ZHANG, W. (2017). Inequality in Beijing: A spatial multilevel analysis of perceived environmental hazard and self-rated health. Annals of the American Association of Geographers, 107(1): 109-129.

PARK, Y. M., KWAN, M. P. (2018): Beyond residential segregation: A spatiotemporal approach to examining multi-contextual segregation. Computers, Environment and Urban Systems, 71: 98-108.

MIYAZAWA, H. [ed.] (2005): Applied Cartography and GIS for Welfare and Well-being. Tokyo, Kokon Shoin. (In Japanese)

NISHIMURA, Y. (2003): Gender Role in the Workplace and the Home in Chinese Cities: A Time-Budget Analysis. Komaba Studies in Human Geography. 16: 105-119. (In Japanese)

NISHIMURA, Y., OKAMOTO, K. (2001): Yesterday and today: Changes in workers' lives in Toyota City, Japan. In: Karan, P. P. [ed.]: Japan in the Bluegrass (pp. 96121). Lexington, University Press of Kentucky.

NISHIMURA, Y., OKAMOTO, K., BOULIDAM, S. (2008): Daily Activity Survey in Lao Suburban Village Using GPS and GIS. Journal of Geography, 117(2): 568-581.

OKAMOTO, K. (1997): Suburbanization of Tokyo and the daily lives of suburban people. In: Karan, P. P., Stapleton, K. [eds.]: The Japanese City. Lexington, University Press of Kentucky, 79-105.

OKAMOTO, K. (2003): China's Urban Transport and Human Activities. Komaba Studies in Human Geography, 16: 4153. (In Japanese)

OKAMOTO, K., ARAI, Y. (2018): Time-geography in Japan: Its application to urban life. In: Ellegård, K. (ed.): Time Geography in the Global Context (pp. 19-40). London, Routledge.

PRED, A. (1973): Urbanisation, domestic planning problems and Swedish geographic research. Progress in Geography, 5: $1-76$.

PRED, A. (1977): The choreography of existence: Comments on Hägerstrand's time-geography and its usefulness. Economic Geography, 53(2): 207-221.

SATAKE, Y., ARAI, Y. (2013): Optical network deployments and the impacts on the internet use in business activities in Higashikawa Town, Hokkaido. Geographical Sciences, 68(3): 153-164. (In Japanese) 
SATAKE, Y., ARAI, Y. (2017): The Challenges of Broadband Deployment in Higashikawa Town, Hokkaido. Quarterly Journal of Geography, 68: 284-301. (In Japanese)

SHAW, S. L., YU, H. (2009): A GIS-based time-geographic approach of studying individual activities and interactions in a hybrid physical-virtual space. Journal of Transport Geography, 17(2): 141-149.

SHEN, Y., CHAI, Y., KWAN, M. P. (2015): Space-time fixity and flexibility of daily activities and the built environment: A case study of different types of communities in Beijing suburbs. Journal of Transport Geography, 47: 90-99.

SHEN, Y., KWAN, M. P., CHAI, Y. (2013): Investigating commuting flexibility with GPS data and 3D geovisualization: a case study of Beijing, China. Journal of Transport Geography, 32: 1-11.

SONG, Y., MILLER, H. J., STEMPIHAR, J., ZHOU, X. (2017): Green accessibility: Estimating the environmental costs of network-time prisms for sustainable transportation planning. Journal of Transport Geography, 64: 109-119.

SUGIURA, S. (2005): Geographical Analysis of Social Services for the Elderly in Japan. Tokyo, Kokon Shoin. (In Japanese)

TA, N., KWAN, M. P., CHAI, Y., LIU, Z. (2016): Gendered Space-Time Constraints, Activity Participation and Household Structure: A Case Study Using A GPS-Based Activity Survey in Suburban Beijing, China. Tijdschrift Voor Economische En Sociale Geografie, 107(5): 505-521.

TAHARA Y. (2003): The Society Aging and Social Welfare Systems for the Elderly in China. Komaba Studies in Human Geography. 16: 79-104. (In Japanese)
THULIN, E., VILHELMSON, B. (2012): The virtualization of urban young people's mobility practices: a timegeographic typology. Geografiska Annaler: Series B, Human Geography, 94(4): 391-403.

WANG, D., CHAI, Y. (2009): The jobs-housing relationship and commuting in Beijing, China: the legacy of Danwei. Journal of Transport Geography, 17(1): 30-38.

WANG, D., CHAI, Y., LI, F. (2011): Built environment diversities and activity-travel behaviour variations in Beijing, China. Journal of Transport Geography, 19(6): 1173-1186.

WANG, D., LI, F., CHAI, Y. (2012): Activity Spaces and Sociospatial Segregation in Beijing. Urban Geography, 33(2): 256-277. doi:10.2747/0272-3638.33.2.256

YUI, Y. [ed.] (2012): Women's Employment and Life Space: Working, Child-rearing and Lifecourse. Tokyo, Akashi Shoten. (In Japanese)

YUI, Y., KAMIYA, H., WAKABAYASHI, Y., NAKAZAWA, T. [eds.] (2004): Urban Spaces of Working Women (In Japanese). Tokyo, Kokon Shoin.

ZHANG, X., CHAI, Y. (2016): "New" time geography: A review of recent progresses of time geographical research from Kajsa Ellegírd in Sweden. (In Chinese). Human Geography, 5: 19-24.

ZHANG, X., WANG, J., KWAN, M. P., CHAI, Y. (2019): Reside nearby, behave apart? Activity-space-based segregation among residents of various types of housing in Beijing, China. Cities, 88: 166-180.

\section{Please cite this article as:}

LI, C., CHAI, Y., ARAI, Y. (2020): The diffusion and development of time-geography in East Asia: The academic life paths of two key scholars. Moravian Geographical Reports, 28(4): 338-352. Doi: https://doi.org/10.2478/mgr-2020-0025 